\title{
Aromatase inhibitors and risk of cardiovascular events in breast cancer patients: a systematic review and meta- analysis
}

Yang $\mathrm{He}^{1,2+}$, Jianhua Zhang ${ }^{3+}$, Guofang Shen ${ }^{4}$, Lin Liu', Qingwei Zhao ${ }^{1}$, Xiaoyang Lư ${ }^{1}$, Hongyu Yang ${ }^{1 *}$ and Dongsheng Hong ${ }^{1 *}$

\begin{abstract}
Background: Cardiovascular events (CVEs) was considered as one of the primary cause to reduce the quality of life in breast cancer patients with aromatase inhibitors (Als) treatment, which has not been sufficiently addressed. The aim of this study was to assess the correlation between risk of CVEs and Als in patients with breast cancer.

Methods: Included studies were obtained from the databases of Embase, Pubmed, Cochrane Library, Clinical Trials.gov, and reference lists. The main outcome measures were overall incidence, odds ratios (ORs), and 95\% confidence intervals (Cls). Furthermore, the association and the risk differences among different tumor types, Als, ages,or treatment regimens were conducted. Fixed-effect or random-effect models were applied in the statistical analyses according to the heterogeneity. Our analysis was performed according to the Preferred Reporting Items for Systematic Reviews and Meta-Analyses (PRISMA) statement.

Results: Seventeen studies, which included 44,411 subjects, were included in our analyses. The overall incidence of CVEs in Als group was 13.02\% (95\% Cl: 8.15-20.17\%) and almost all of the high-grade CVEs occurred in patients treated with Als. The pooled ORs of CVEs was 0.9940 (95\% Cl: 0.8545-1.1562). Under sub-group analysis, the incidence of CVEs related to exemestane was higher than that of controls (OR $=1.1564,95 \% \mathrm{Cl}$ : 1.0656-1.2549), but no statistical differences in risk of CVEs were found in other sub-group analysis. No evidence of publication bias was found for incidence of CVEs in our meta-analysis by a funnel plot.

Conclusions: These results suggest that patients with breast cancer treated with Als do not have a significant risk of developing CVEs in comparison with the controls, and exemestane might not be considered as the alternative Al to the breast cancer patients from the perspective of CVEs. Further studies are recommended to investigate this association and the risk differences among different tumor types, Als or treatment regimens.
\end{abstract}

Keywords: Breast cancer, Aromatase inhibitors, Cardiovascular events, Meta-analysis

\footnotetext{
* Correspondence: hongyuyang@zju.edu.cn; hdswell@zju.edu.cn

${ }^{\dagger}$ Yang He and Jianhua Zhang contributed equally to this work.

'Department of Pharmacy, the First Affiliated Hospital, College of Medicine,

Zhejiang University, 79 Qingchun Road, Hangzhou 310003, People's Republic

of China

Full list of author information is available at the end of the article
}

(c) The Author(s). 2019 Open Access This article is distributed under the terms of the Creative Commons Attribution 4.0 International License (http://creativecommons.org/licenses/by/4.0/), which permits unrestricted use, distribution, and reproduction in any medium, provided you give appropriate credit to the original author(s) and the source, provide a link to the Creative Commons license, and indicate if changes were made. The Creative Commons Public Domain Dedication waiver (http://creativecommons.org/publicdomain/zero/1.0/) applies to the data made available in this article, unless otherwise stated. 


\section{Background}

Breast cancer is an increasing public health problem throughout the world, which is one of the most common malignancies and causes for tumor-related deaths among women [1-3]. Fortunately, The 5-year survival rate for patients with breast cancer has elevated from an average of $53 \%$ in 2007 to $85 \%$ in 2012 and the number is still rising in recent year $[4,5]$. However, this positive trend in improved cancer-related mortality is weakened by an emerging increase in cardiovascular (CV) morbidity and mortality in these patients. It is estimated that over $\$ 800$ million will be spent annually in the US on providing CV care for these women with breast cancer $[2,6]$. Several recently published research studies have studied possible etiologies of these events, and it is suggested that the increased morbidity of CV disease and events has a temporal relationship with the administration of chemotherapy for cancer [7-11]. Nevertheless, the causes for this increase in cardiovascular related events has not been clearly demonstrated.

Anastrozole, letrozole, and exemestane are the three proven aromatase inhibitors (AIs), and several large randomized control trials (RCTs) have demonstrated the advantage of the AIs compared with tamoxifen [12-14].AIs have systematically been clarified to increase the incidence of genitourinary and musculoskeletal discomfort compared to the control group $[15,16]$, and of symptoms related to fractures [17]. However, the potential impact on cardiovascular system has not been sufficiently elucidated, and patients with cardiovascular disease risk is difficult to identify. Cardiovascular events (CVEs) related to breast cancer include hypertension, ischemic cardiovascular disease, venous thrombosis, hypercholesterolaemia, arrhythmia, cardiac failure, peripheral arterial disease, embolism, myocardial infarction, atrial fibrillation [18-21]. Data regarding the CVEs in AIs treated patients was reported in several RCTs, several of these reporting increased risks with AIs [7, 22-24]. However, recent study suggested that AIs may not increase the risk of the most fatal cardiovascular events [9]. In consideration of CVEs could greatly reduce the quality of life in breast cancer patients. Thus it is of great importance to fully understand the incidence of CVEs related to AIs treatment. Therefore, we conducted a systematic review and meta-analysis to evaluate the association of AI therapies with CVEs.

\section{Methods}

\section{Search strategy}

A systemic search was conducted on PubMed (from 1967), Embase (from 1974), and the Cochrane Library electronic databases at the end of December 2017. The keywords 'Aromatase inhibitors', 'Breast cancer', 'Randomized controlled trials', 'Clinical trials' and 'Controlled clinical trials' were used for the search. Moreover, we also searched for registered clinical trials on ClinicalTrials.gov. Only clinical trials and articles published in English were included in this study. This study is an meta-analysis and not involves subjects, ethical approval was not required.

\section{Study selection and quality assessment}

All studies were assessed by two review investigators ( $\mathrm{HY}$ and $\mathrm{ZJH}$ )independently. Trials which were judged as pertinent by one of the investigators were retrieved for further consideration. All identified discrepancies were identified and resolved by consensus. Clinical trials were included in the current study if they met the following criteria:

a. The trial involved patients diagnosed with breast cancer.

b. The trial was prospective phase II or III RCTs and involved subjects receiving AIs treatment.

c. The data for events of CVEs was available in the trial.

The Jadad scale was used to assess the quality of each included trail. A higher score in the range of 0 to 5 indicated a high quality [25].

\section{Data extraction and clinical endpoints}

Two investigators (HY and $\mathrm{ZJH}$ ) performed data extraction independently. The following information was extracted from each trial: first author's name, year of publication, trials phase, ethnicity, number of patients in the AIs and control groups, CVEs. These clinical end points were obtained according to the Common Terminology Criteria for Adverse Events (CTCAE) of National Cancer Institute (https:// ctep.cancer.gov/protocolDevelopment/electronic_appli cations/ctc.htm), and a variety of CVEs, such as hypertension, ischemic cardiovascular disease, venous thrombosis, hypercholesterolaemia, arrhythmia, cardiacfailure, peripheral arterial disease, embolism, myocardial infarction and atrial fibrillation were included. A composite of all-cause mortality and cardiac events, such as non-fatal myocardial infarction, new atrial fibrillation or heart failure episode requiring hospitalization was used as a primary end point in the risk assessment of CVEs, and secondary end points comprised the primary end point composite factors. The primary end point was defined as the time from cancer diagnosis to the first occurrence of any component of the composite major adverse cardiovascular event outcome.

\section{Data analysis}

The data analysis was carried out in accordance with the Preferred Reporting Items for Systematic Reviews and Meta-Analyses (PRISMA) statement [26, 27] The major indexes were incidence, odds ratio (OR), and corresponding 
95\% CIs of relevant CVEs. CVEs Subjects and the total number of subjects in groups with AIs treatment were extracted from the safety profiles of included trials to calculate CVEs incidence. The confidence level sets the boundaries of a confidence interval (CI), and it is conventionally set at 95\% to coincide with the $5 \%$ convention of statistical significance in hypothesis testing. A 95\% CI is the interval that you are $95 \%$ certain contains the true population value as it might be estimated from a much larger study. From each trial, we derived the proportion and 95\% CI of patients developed CVEs. For trials with a control group, we further derived the OR of CVEs. For trials reporting no CVEs in any group, the OR and variance was obtained using classic half-integer continuity correction. The data was tested for heterogeneity and among-study inconsistency using the Cochrane's Q statistic and $\mathrm{I}^{2}$ tests respectively $[28,29]$. The statistical significance of heterogeneity was marked by a $P<0.1$ or $\mathrm{I}^{2}>40 \%$. The random-effects model was applied for data analysis when heterogeneity existed. Otherwise, a fixed-effects model was selected. A $p$-value $<0.05$ was considered statistically significant. The publication bias was estimated by the Begg's and Egger's test and a contour-enhanced funnel plots was conducted to futher evaluate the publication bias and enhance interpretation of a funnel plot by helping distinguish publication bias from other cause of funnel plot asymmetry [30-32]. Meta-Analyses (PRISMA) Statement was shown in the Additional file 5: Table S1. All data analyses were performed by using $\mathrm{R}$ software, version 3.2.3 (The $\mathrm{R}$ foundation for statistical computing, http://www.r-project.org) .

\section{Results}

\section{Search results and trial characteristics}

Through initial research, 11,911 potentially relevant studies were identified. After reviewing titles and abstracts, 3555 studies were performed for full-text evaluation. Ultimately, 17 studies met our inclusion criteria, and 44,411 subjects were included in our analyses [33-49]. Figure 1 outlines the selection process in detail. Of these, 15 RCTs were based in Europe [33, 35-48], 8 in North America $[35,37,38,43,45-47] 6$ in the Asia-Pacific region $[34,35,38,43,45,46]$, and several international multicenter clinical studies were included. The baseline age of subjects ranged from 29 to 96 years [35, 45]. The duration of the followup times ranged from 11.4 to 100 months $[39,40]$, but the majority had 30-month followup times. The quality of the 17 studies was high: five studies had Jadad scores of 5 , six studies had Jadad scores of 4 ,and six studies had Jadad scores of 3 . The detailed information is shown in Tables 1 and 2 .

\section{Overall incidence of CVEs in Als group}

A total of 59,503 subjects from the seventeen studies were available for incidence of CVEs analysis [33-49].CVEs were reported in all studies, and it ranged from 1.1 to

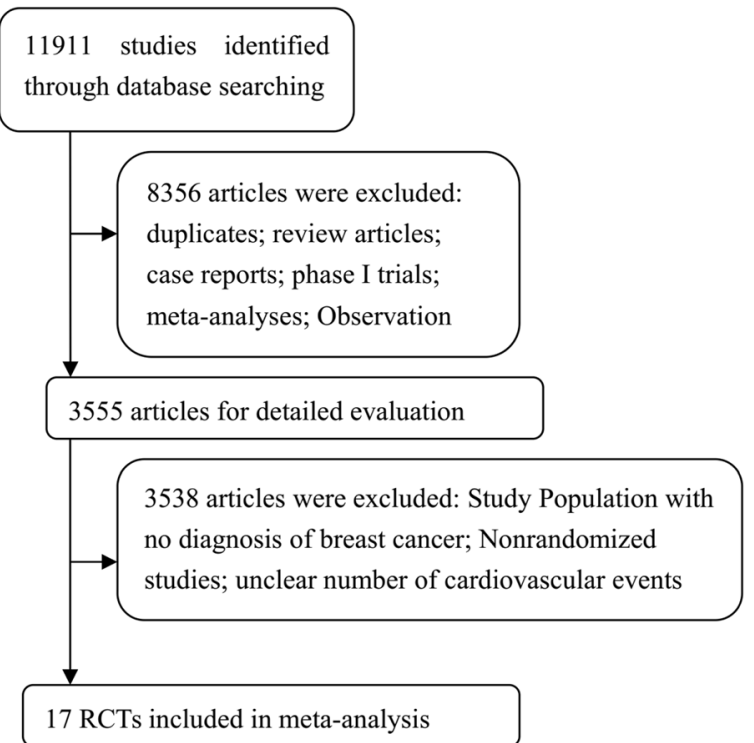

Fig. 1 Flow chart demonstrating process of study selection

60.6\% in AIs group. The highest incidence of CVEs was from a phase III trials of North America, which all subjects were confirmed early-stage breast cancer [47]. Based on data from each study, the calculated overall incidence of CVEs was 13.02\%(95\% CI: 8.15-20.17\%, Fig. 2) according to the random effects model.

High-grade CVEs were reported in 10 out of 17 studies, and it ranged from 0.34 to $24.42 \%$. The highest incidence of high-grade CVEs was from a phase III trials of Europe, which all subjects were confirmed early-stage breast cancer [42]. Based on data from each study, the calculated overall incidence of high-grade CVEs was $3.75 \%(95 \%$ CI: $1.66-8.24 \%$, Additional file 1: Figure S1) according to the random effects model.

\section{Odds ratios of CVEs}

To evaluate the specific contribution of AIs to the development of CVEs in subjects excluding the influence of many confounding factors such as the history of course of disease, we performed the OR of CVEs between AIs and control groups. Of the 29,495 subjects from seven trials were included in OR analysis. The pooled OR for CVEs showed that treatment with AIs do not significantly increased the risk of developing CVEs in breast cancer patients with an OR of 0.9940 (95\% CI: 0.8545-1.1562, $p=0.01$, Fig. 3), according to the random effects model. The most significant difference OR was 1.1653 (95\% CI: 1.0388-1.3073) occurred in a phase III study from North America [47], and high-grade CVEs occurred in ten trials [34, 35, 38, 40-43, 45-47]. Almost all of the high-grade CVEs occurred in patients treated with AIs. 


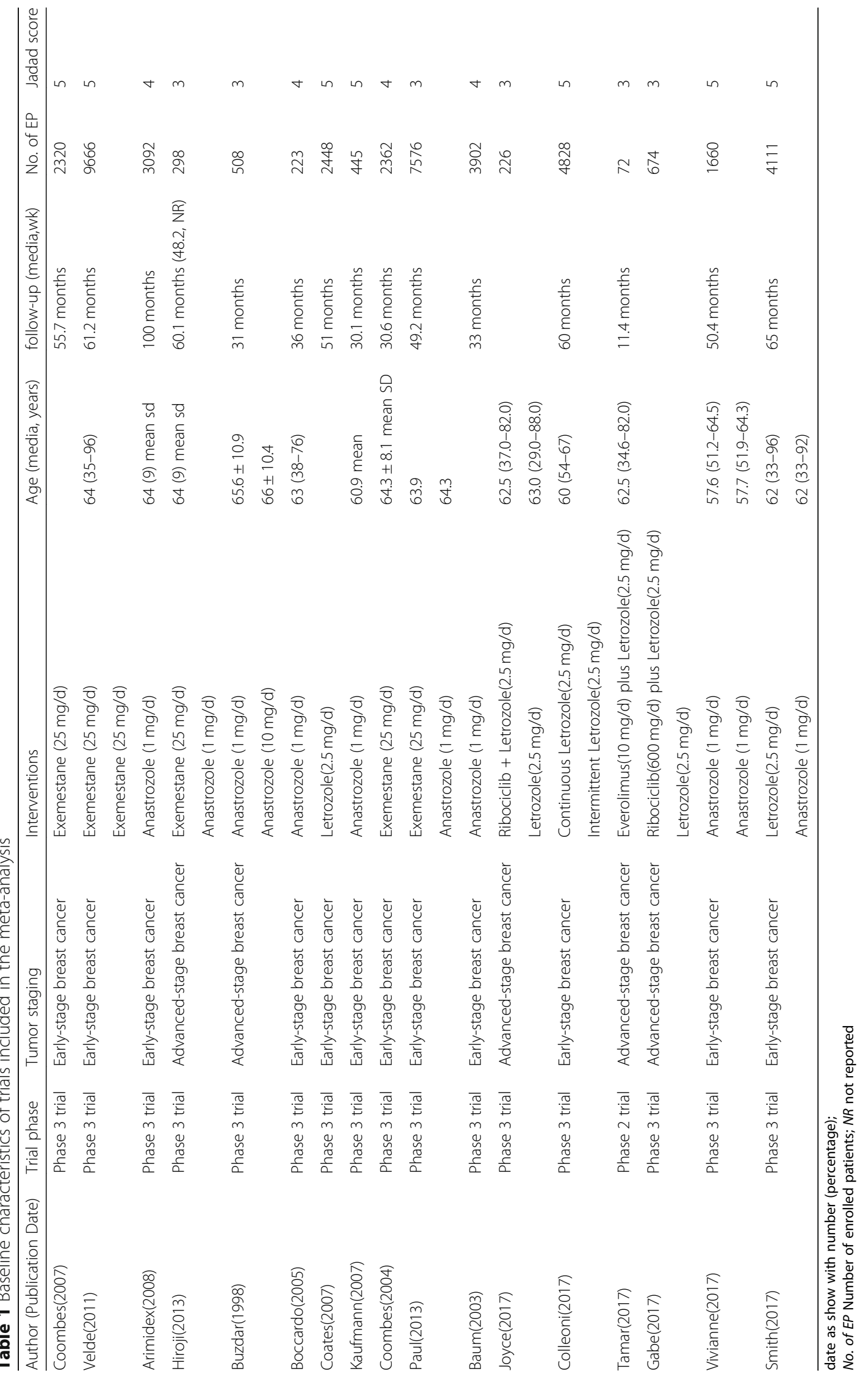


Table 2 Fatal or high-grade CVEs of Aromatase Inhibitors in Patients with breast cancer in our study

\begin{tabular}{|c|c|c|c|c|c|c|c|c|}
\hline \multirow{2}{*}{$\begin{array}{l}\text { Author } \\
\text { (Publication } \\
\text { Date) }\end{array}$} & \multicolumn{8}{|l|}{ Events of CVEs } \\
\hline & Hypertension & $\begin{array}{l}\text { Ischaemic CV } \\
\text { Disease }\end{array}$ & $\begin{array}{l}\text { Venous } \\
\text { thrombosis }\end{array}$ & Hypercholesterolaemia & Arrhythmia & $\begin{array}{l}\text { Cardiac } \\
\text { Failure }\end{array}$ & $\begin{array}{l}\text { Peripheral Arterial } \\
\text { Disease }\end{array}$ & Embolism \\
\hline $\begin{array}{l}\text { Coombes } \\
\text { (2007) }\end{array}$ & 2 & 4 & 7 & 0 & NR & NR & NR & $N R$ \\
\hline Velde(2011) & 126 & 76 & 83 & NR & 93 & 54 & 14 & 45 \\
\hline Arimidex(2008) & NR & NR & NR & NR & NR & NR & NR & $N R$ \\
\hline Hiroji(2013) & 3 & $N R$ & $N R$ & NR & NR & NR & NR & $N R$ \\
\hline Buzdar(1998) & $N R$ & NR & NR & $N R$ & $N R$ & NR & NR & $N R$ \\
\hline Boccardo(2005) & NR & NR & $N R$ & NR & NR & NR & NR & NR \\
\hline Coates(2007) & NR & 42 & NR & 10 & NR & 14 & NR & 25 \\
\hline Kaufmann(2007) & NR & NR & NR & $N R$ & $N R$ & NR & NR & $N R$ \\
\hline Coombes(2004) & NR & NR & NR & NR & NR & NR & NR & NR \\
\hline Paul(2013) & NR & NR & NR & NR & NR & NR & NR & NR \\
\hline Baum(2003) & NR & NR & NR & NR & $N R$ & NR & NR & NR \\
\hline Joyce(2017) & 28 & NR & $N R$ & $N R$ & $N R$ & NR & NR & $N R$ \\
\hline Colleoni(2017) & 1101 & 40 & NR & NR & $N R$ & NR & NR & 38 \\
\hline Tamar(2017) & NR & NR & NR & 1 & $N R$ & NR & NR & $N R$ \\
\hline Gabe(2017) & 69 & NR & NR & NR & NR & NR & NR & NR \\
\hline Vivianne(2017) & NR & NR & $N R$ & $N R$ & NR & NR & NR & $N R$ \\
\hline Smith(2017) & 45 & NR & NR & 3 & NR & NR & NR & NR \\
\hline
\end{tabular}

date as show with number (percentage);

No. of EP Number of enrolled patients; NR not reported

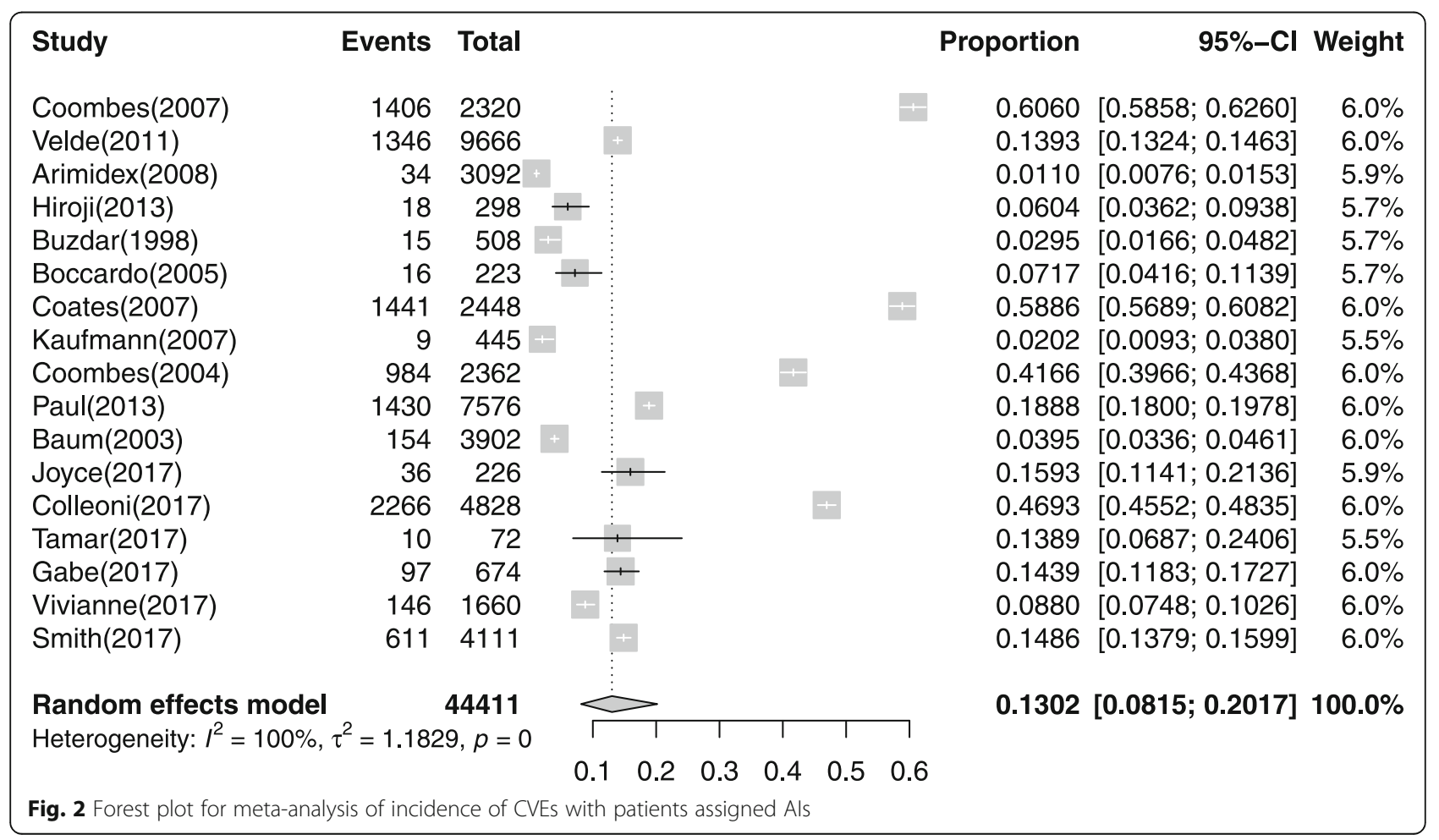




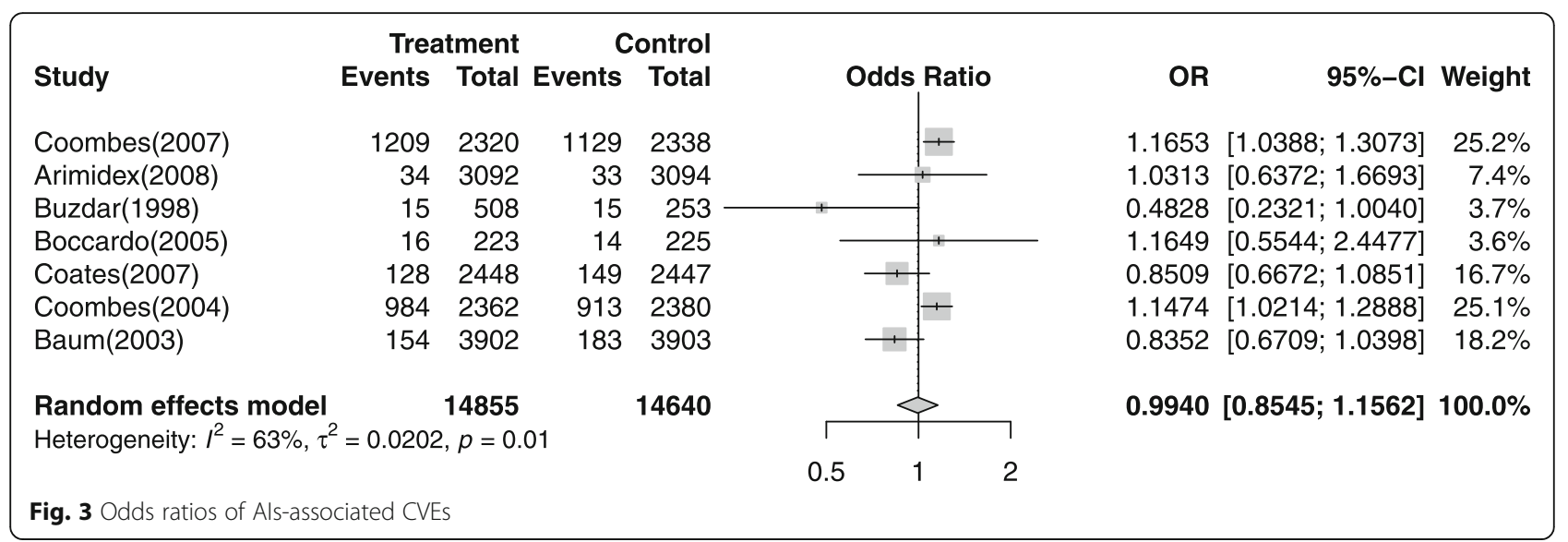

\section{Sub-group analysis}

The incidence of CVEs might be different among different tumor stages, AIs or treatment regimens. Thus, sub-group analysis was conducted according to under- lying malignancies, AIs and follow-up periods, although there is no significantly difference on the overall incidence of CVEs between patients with AIs treatment and that of non-AIs patients. There was no significant variation in the incidence of CVEs between different tumor stages (Additional file 2: Figure $\mathrm{S} 2$ ), even if the patients with advanced-stage breast cancer has often been thought of as the possible high risk factor for CVEs. Then, the incidence differences among follow-up periods were investigated and there was no significant variation of the incidence of CVEs between long time and short time follow-up periods in patients received AIs (Additional file 3: Figure S3). Additionally, we found that the incidence of CVEs related to anastrozole and letrozole was slightly higher than controls, though statistically it makes no difference. However, it is worth mentioning that the incidence of CVEs related to exemestane was higher than that of controls (OR $=1.1564,95 \% \mathrm{CI}: 1.0656-1.2549$, Fig. 4), which suggested that exemestane might not be considered as the alternative AI to the breast cancer patients from the perspective of CVEs.

\section{Publication bias}

No evidence of publication bias was found for the OR of CVEs in our meta-analysis by a funnel plot (Fig. 5) and

\begin{tabular}{|c|c|c|c|c|c|c|c|c|c|c|}
\hline \multirow[b]{2}{*}{ Study } & \multicolumn{2}{|c|}{ Treatment } & \multicolumn{2}{|c|}{ Control } & \multirow{2}{*}{\multicolumn{2}{|c|}{ Odds }} & \multirow[b]{2}{*}{ Ratio } & \multirow[b]{2}{*}{ OR } & \multirow[b]{2}{*}{$95 \%-\mathrm{Cl}$} & \multirow[b]{2}{*}{ Weight } \\
\hline & Events & Total E & vents & Total & & & & & & \\
\hline \multicolumn{11}{|l|}{ group $=$ Anastrozole } \\
\hline Arimidex(2008) & 34 & 3092 & 33 & 3094 & & & 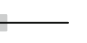 & 1.0313 & {$[0.6372 ; 1.6693]$} & $7.4 \%$ \\
\hline Buzdar(1998) & 15 & 508 & 15 & 253 & & & & 0.4828 & {$[0.2321 ; 1.0040]$} & $3.7 \%$ \\
\hline Boccardo(2005) & 16 & 223 & 14 & 225 & & & I & 1.1649 & {$[0.5544 ; 2.4477]$} & $3.6 \%$ \\
\hline Baum(2003) & 154 & 3902 & 183 & 3903 & & $\rightarrow$ & & 0.8352 & {$[0.6709 ; 1.0398]$} & $18.2 \%$ \\
\hline Random effects model & & 7725 & & 7475 & & $\infty$ & & 0.8533 & {$[0.6707 ; 1.0854]$} & $33.0 \%$ \\
\hline \multicolumn{11}{|c|}{ Heterogeneity: $I^{2}=17 \%, \tau^{2}=0.0127, p=0.30$} \\
\hline \multicolumn{11}{|l|}{ group = Exemestane } \\
\hline Coombes(2007) & 1209 & 2320 & 1129 & 2338 & & & + & 1.1653 & {$[1.0388 ; 1.3073]$} & $25.2 \%$ \\
\hline Coombes(2004) & 984 & 2362 & 913 & 2380 & & & + & 1.1474 & {$[1.0214 ; 1.2888]$} & $25.1 \%$ \\
\hline Random effects model & & 4682 & & 4718 & & & $\diamond$ & 1.1564 & {$[1.0656 ; 1.2549]$} & $50.3 \%$ \\
\hline \multicolumn{11}{|c|}{ Heterogeneity: $I^{2}=0 \%, \tau^{2}=0, p=0.85$} \\
\hline \multicolumn{11}{|l|}{ group $=$ letrozole } \\
\hline Coates (2007) & 128 & 2448 & 149 & 2447 & & $\rightarrow$ & & 0.8509 & {$[0.6672 ; 1.0851]$} & $16.7 \%$ \\
\hline $\begin{array}{l}\text { Random effects model } \\
\text { Heterogeneity: not applicabl }\end{array}$ & & 2448 & & 2447 & & $<$ & & 0.8509 & {$[0.6672 ; 1.0851]$} & $16.7 \%$ \\
\hline Random effects model & & 14855 & & 14640 & & & 8 & 0.9940 & {$[0.8545 ; 1.1562]$} & $100.0 \%$ \\
\hline \multirow{2}{*}{\multicolumn{4}{|c|}{ Heterogeneity: $I^{2}=63 \%, \tau^{2}=0.0202, p=0.01$}} & & $\Gamma$ & & & & & \\
\hline & & & & & 0.5 & 1 & 1 & & & \\
\hline
\end{tabular}




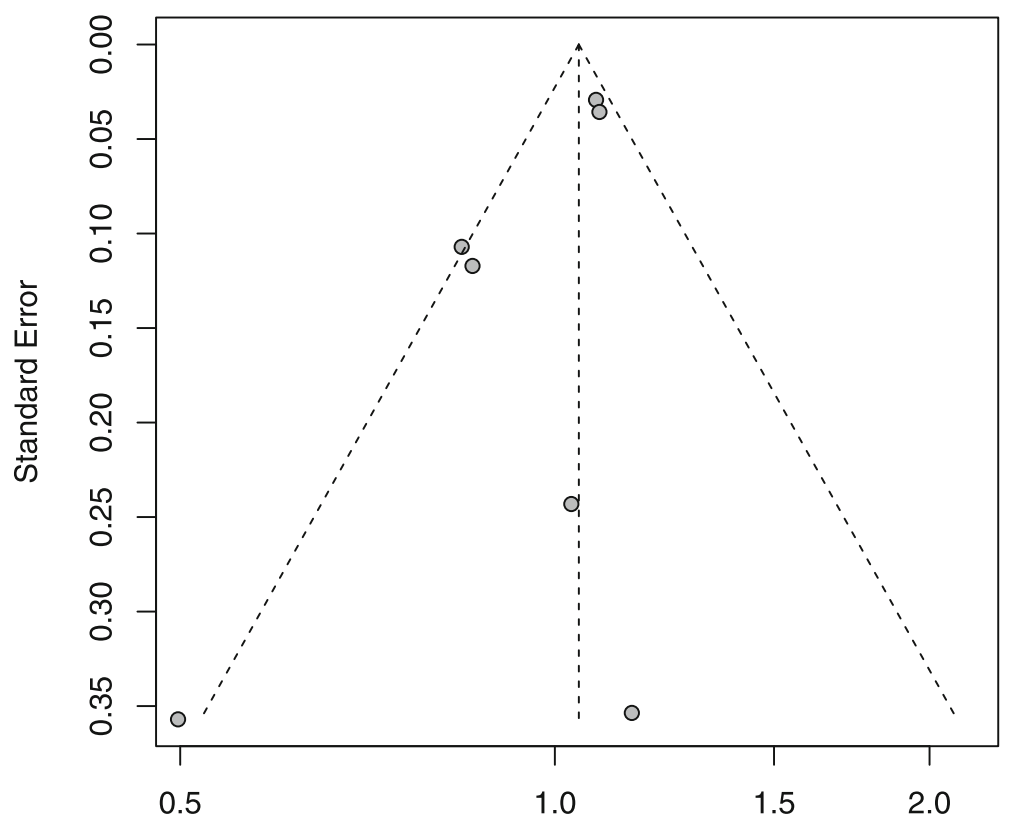

Risk Ratio

Fig. 5 Funnel plot standard error by OR of CVEs

contour-enhanced funnel plots (Additional file 4: Figure S4 )[32].

\section{Discussion}

It is found that CV disease and breast cancer have several overlapping risk factors, such as obesity and smoking, meanwhile cardiovascular events (CVEs) is considered as one of the major causes of death in breast cancer patients undergoing chemotherapy, and AIs may contribute to the development of CVEs [7, 50-52]. For older women, the $\mathrm{CV}$ disease may pose a greater mortality threat than breast cancer itself [7]. Therefore, it is vital for clinicians and patients to realize the risk of CVEs related to cancer treatment, so as to optimize the treatment strategy and actively manage these adverse events. Aromatase inhibitors (AIs) are used as standard medication therapies for most breast cancer patients [53]. However, its impact on the development of CVEs has not been sufficiently elucidated. Meanwhile, reliable data about the risk of CVEs in breast cancer patients treated with AIs is still scantly. Thus, we conducted this study to assess the risk and incidence of CVEs in breast cancer patients receiving AIs.

To our knowledge, this is the latest study to assess the CVEs risk of AIs treatment in breast cancer patients. Under the previous study, it was suggested that AIs were associated with a $19 \%$ (RR: $1.19,95 \%$ CI: $1.07-1.34$ ) increased risk of cardiovascular events compared with tamoxifen, and cardioprotective effects of the tamoxifen was considered to be accounted for the increased risk of cardiovascular events with AIs [51, 54]. However, it was indicated in our study that breast cancer treated with AIs do not have a significant risk of developing CVEs in comparison with the controls. However, the incidence of CVEs related to exemestane was higher than that of controls $(\mathrm{OR}=1.1564,95 \%$ CI: 1.0656-1.2549, Fig. 4) according to our sub-group analysis. Moreover, exemestane has a special role in the sequence of AIs during treatment of metastatic breast cancer as the drug may cause new responses following progression on non-steroidal AIs [35, 47]. Thus, it might be the other disadvantage to choose exemestane upfront based on very week data concerning the risk of CVEs. Furthermore, it was found that the the highest incidence of CVEs associated with AIs in breast cancer patients was $60.6 \%$, and the lowest incidence of CVEs is $1.1 \%$. The overall incidence of CVEs associated with AIs in breast cancer patients was $13.02 \%$. In addition, the highest OR of developing CVEs with AIs versus controls in breast cancer patients was 1.1653, and the pooled OR of developing CVEs was 1.0760. More importantly, High-grade CVEs occurred in ten trials [34, 35, 38, 40-43, 45-47], and almost all of the high-grade CVEs occurred in patients treated with AIs.

Providing systemic education for breast cancer patients are important for proper management of AIs-induced CVEs. CVEs in breast cancer patients commonly including hypertension, ischemic cardiovascular disease, venous thrombosis, hypercholesterolaemia, arrhythmia, cardiac failure, peripheral arterial disease, embolism,myocardial infarction,atrial fibrillation [18-21] Usually, the incidence of CVEs is at the highest in the initial months of drug treatment and in the last stage of disease progression. On 
the contrary, the incidence is lower while patients responded to treatment. CVEs can lead to dose reduction and drug discontinuation in clinical treatment for breast cancer patients. Our findings clarified that the incidence of CVEs was higher in breast cancer patients receiving AIs compared to controls. In addition, the continued monitoring, effective and preventive management of CVEs are important for continued AI treatment in breast cancer patients [55]. Thus, it is very important to educate both patients and physicians about the complication and prevention.

Development of an integrated disease evaluation system which is scientific, reasonable and practical for the prediction of CVEs in AI treated patients remains a key problem for clinicians. Immediate and accurate diagnosis is essential to reduce the incidence of AIs-related CVEs. However, some major cardiovascular events, such as myocardial infarction and stroke in individuals often appear without known pre-existing cardiovascular disease, and it increases the difficulty of health management in patients with breast cancer. The prevention of CVEs and the accurate risk assessment for breast cancer patients, remains to be serious public health challenges. The developed scoring equations which use cardiovascular risk factors to predict high risk population, tend to have limited accuracy. For example, the Framingham Risk Score (FRS) which is often considered the reference standard, tend to over-estimate risk in low risk populations and under-estimate risk in high risk populations. Thus, it is recommended to incorporate more risk markers or indications, such as metabolic syndrome, plasma $\mathrm{C}$-reactive protein $(\mathrm{C}-\mathrm{RP})$, coronary artery calcium $(\mathrm{CAC})$, carotid intima media thickness (IMT) and the ankle brachial index (ABI) are incorporated to improve the prediction of CVEs [56]. All breast cancer patients with high risk factor for the development of AIs-induced CVEs should be carefully and cautiously cared by physicians, as well as the members of home care team.

The reasons for AIs-induced CVEs in patients with breast cancer is still confusing. The confounding factors of CVEs in breast cancer patients may from age-related condition, drug therapies or disease itself. AIs-related organ dysfunctions, such as digestive tract mucosa injury, lung and/ or renal injury also increase the incidence for CVEs [57, 58]. Older patients who suffer from physiological dysfunction and senile disease making them more susceptible to $\mathrm{CV}$ diseases, and physician should be aware of this while caring for these patient $[59,60]$. It was shown that dietary supplements such as folic acid, vitamins B6 and vitamins B12, may reduce the rate of cardiovascular diseases, but it is uncertain if vitamin B supplementation reduces the risk of CVEs. Furthermore, recent studies with vascular diseases failed to prove the association between B-vitamin supplementation and cardiovascular diseases [13], and it needs further verification [5]. Furthermore, limited drugs such as beta blockers and angiotensin-converting enzyme inhibitors (ACEIs) were recommended to be indicated in asymptomatic patients in order to minimize the effects of chemotherapy on myocardial dysfunction, but it hasn't been verified on patients with breast cancers [61]. Notably, practice guidelines for cancer treatments and cardiovascular toxicity was published by the the European Society of Cardiology (ESC) in 2016, so as to provide prevention and treatment strategies for CVEs [8].

Several limitations are presented in our study. Firstly, this is a meta-analysis based on previous studies and not on patient data. It is difficult to determine how the different event severity and timing of events might affect the current analyses. Moreover, there are a mix of advanced or metastatic and early breast cancer studies included in present study, and patients with metastatic breast cancer may have been exposed to a greater number of prior treatments that may also induced cardiotoxicity such as radiotherapy or anthracycline chemotherapy [62-66], which might affect cardiovascular outcomes. Thus, all of these above confounding variables including basic medication history and adjuvant therapy could not be considered in the analysis. Secondly, this meta-analysis is performed in patients with proper organ function, so the risk and sensitivity of CVEs may be higher in routine clinical practice. Thirdly, the studies were performed at various types of institutions by different researchers in this meta-analysis, and the evaluating and conclusion may be existed heterogeneous. In addition, the majority of studies have been conducted in Europe and America, which has limited the possibility to generalize the results. The limitations of the current study mean that high-quality RCTs with a large sample size are still needed to reliably evaluate the risk of AIs induced CVEs in patients with breast cancer.

Cancer-free survival rate has improved over the past 20 years for many individuals with breast cancer. However, chemotherapy associated CVEs compromised the improvement in cancer related survival [60]. As a result, there is an emerging need to obtain valuable data to optimize medical scheme for chemotherapy in patients with breast cancer by reducing the risk of CVEs. Our study showed that the incidence of CVEs in AIs group was higher compared with the controls, meanwhile almost all of high-grade CVEs occurred in patients treated with AIs. Adverse events monitoring is particularly important in reducing CVEs for AIs treatment. Optimal management and accurate diagnosis of CVEs for breast cancer patients is critical for safe medication. Besides, there is an emerging need to develop accurate, cost-effective methods to identify those individuals treated for cancer at increased risk of CVEs. 


\section{Conclusions}

In conclusion, our results suggest that patients with breast cancer treated with AIs dose not significant risk of developing CVEs in comparison with the controls. Further studies are recommended to investigate this association and the risk differences among different tumor types, AIs, ages,or treatment regimens.

\section{Supplementary information}

Supplementary information accompanies this paper at https://doi.org/10. 1186/s40360-019-0339-1.

Additional file 1; Figure S1. Forest plot for meta-analysis of incidence of High-grade CVEs with patients assigned Als.

Additional file 2: Figure S2. Sub-group analysis of the incidence of CVEs between different tumor stages.

Additional file 3: Figure S3. Sub-group analysis of the incidence of CVEs between long time( $\geq 24$ months) and short time follow-up periods.

Additional file 4: Figure S4. The contour-enhanced funnel plot for standard error by OR of CVEs.

Additional file 5: Table S1. PRISMA 2009 checklist for systematic review.

\section{Abbreviations}

ABI: Ankle brachial index; ACEls: Angiotensin-converting enzyme inhibitors; Als: Aromatase inhibitors; CAC: Coronary artery calcium; Cl: Confidence interval; C-RP: C-reactive protein; CV: Cardiovascular; CVEs: Cardiovascular events; IMT: Intima media thickness; RCTs: Randomized control trials

\section{Acknowledgements}

The author would like to thank Dr. Ziqi Ye (MD), from the Department of Pharmacy, the First Affiliated Hospital, College of Medicine, Zhejiang University, Hangzhou, Zhejiang, China for his immense contribution to the interpretation of the results.

\section{Authors' contributions}

YHY and HDS conceived the idea of the study; HY and ZJH acquired and analysed the data; YHY, HY and SGF drafted the initial manuscript; LL, ZQW LXY and HDS interpreted the results and revised it critically for important intellectual content. All authors discussed the results and approved the final version.

\section{Funding}

This research was supported by the National Natural Science Foundation of China $(81302765,81503256)$ and Medical Technology Program of Zhejiang Province (2015KYA095,2018KY074), including the design of the study and collection, analysis, and interpretation of data and in writing the manuscript.

\section{Availability of data and materials}

All data and materials used in this research are freely available in electronic databases (PubMed, EMBASE, Cochrane database, www.ClinicalTrials.gov) and references have been provided. The datasets used and analysed during the current study are available from the corresponding author on reasonable request.

All data generated or analysed during this study are included in this published article and its supplementary information files.

\section{Ethics approval and consent to participate}

Not applicable.

\section{Consent for publication}

Not applicable.

\section{Competing interests}

The authors declare that they have no competing interests.

\section{Author details}

'Department of Pharmacy, the First Affiliated Hospital, College of Medicine, Zhejiang University, 79 Qingchun Road, Hangzhou 310003, People's Republic of China. ${ }^{2}$ College of Medicine, Zhejiang University, 866 Yuhangtang Road, Hangzhou 310003, People's Republic of China. 'Department of Management, the Logistics Service Center of Municipal Government, Hangzhou 310019, People's Republic of China. ${ }^{4}$ Loma Linda University School of Pharmacy, Loma Linda, CA 92354, USA.

Received: 11 July 2019 Accepted: 20 September 2019

Published online: 29 October 2019

\section{References}

1. Tyagi NK, Dhesy-Thind S. Clinical practice guidelines in breast cancer. Curr Oncol. 2018;25(Suppl 1):S151-60

2. Coughlin SS, Ekwueme DU. Breast cancer as a global health concern. Cancer Epidemiol. 2009;33(5):315-8.

3. Wockel A, Albert US, Janni W, Scharl A, Kreienberg R, Stuber T. The screening, diagnosis, treatment, and follow-up of breast Cancer. Dtsch Arztebl Int. 2018;115(18):316-23.

4. Patnaik JL, Byers T, DiGuiseppi C, Dabelea D, Denberg TD. Cardiovascular disease competes with breast cancer as the leading cause of death for older females diagnosed with breast cancer: a retrospective cohort study. Breast Cancer Res. 2011;13(3):R64.

5. Vasu S, Hundley WG. Understanding cardiovascular injury after treatment for cancer: an overview of current uses and future directions of cardiovascular magnetic resonance. J Cardiovasc Magn Reson. 2013;15:66.

6. Brenner $\mathrm{H}$. Long-term survival rates of cancer patients achieved by the end of the 20th century: a period analysis. Lancet. 2002;360(9340):1131-5.

7. Mehta LS, Watson KE, Barac A, Beckie TM, Bittner V, Cruz-Flores S, Dent S, Kondapalli L, Ky B, Okwuosa T, et al. Cardiovascular disease and breast Cancer: where these entities intersect: a scientific statement from the American Heart Association. Circulation. 2018;137(8):e30-66.

8. Zamorano JLLPRM, Group. ESD. 2016 ESC Position paper on cancer treatments and cardiovascular toxicity developed under the auspices of the ESC Committee for practice guidelines: the task force for cancer treatments and cardiovascular toxicity of the European Society of Cardiology (ESC). Eur Heart J. 2016;36(37):2768-801.

9. Haque R, Shi J, Schottinger JE, Chung J, Avila C, Amundsen B, Xu X, Barac A, Chlebowski RT. Cardiovascular disease after aromatase inhibitor use. JAMA Oncol. 2016;2(12):1590-7.

10. Rozner RN, Frishman WH. Cardiovascular effects of chemotherapy used in the treatment of breast cancers. Cardiol Rev. 2019;27(2):87-96.

11. Houston TP, Ostroff JS. Cardiovascular risk factors and breast Cancer. J Clin Oncol. 2018;36(27):2810.

12. Yang $Y$, Pan $W$, Tang $X$, Wu S, Sun $X$. A meta-analysis of randomized controlled trials comparing the efficacy and safety of anastrozole versus tamoxifen for breast cancer. Oncotarget. 2017:8(29):48362-74.

13. Munzone E, Giobbie-Hurder A, Gusterson BA, Mallon E, Viale G, Thurlimann B, Ejlertsen B, MacGrogan G, Bibeau F, Lelkaitis G, et al. Outcomes of special histotypes of breast cancer after adjuvant endocrine therapy with letrozole or tamoxifen in the monotherapy cohort of the BIG 1-98 trial. Ann Oncol. 2015;26(12):2442-9.

14. Paridaens RJ, Dirix LY, Beex LV, Nooij M, Cameron DA, Cufer T, Piccart MJ, Bogaerts J, Therasse P. Phase III study comparing exemestane with tamoxifen as first-line hormonal treatment of metastatic breast cancer in postmenopausal women: the European Organisation for Research and Treatment of Cancer breast Cancer cooperative group. J Clin Oncol. 2008; 26(30):4883-90.

15. Sousa MS, Peate M, Jarvis S, Hickey M, Friedlander M. A clinical guide to the management of genitourinary symptoms in breast cancer survivors on endocrine therapy. Ther Adv Med Oncol. 2017;9(4):269-85.

16. Campbell A, Heydarian R, Ochoa C, Dwivedi AK, Nahleh ZA. Single arm phase II study of oral vitamin B12 for the treatment of musculoskeletal symptoms associated with aromatase inhibitors in women with early stage breast cancer. Breast J. 2018;24(3):260-8

17. Grossmann M, Ramchand SK, Milat F, Vincent A, Lim E, Kotowicz MA, Hicks $\mathrm{J}$, Teede $\mathrm{H}$. Assessment and management of bone health in women with oestrogen receptor-positive breast cancer receiving endocrine therapy: position statement of the Endocrine Society of Australia, the Australian and New Zealand bone \&amp; mineral society, the Australasian menopause 
society and the clinical oncology Society of Australia. Clin Endocrinol. 2018; 89(3):280-96.

18. Kawaguchi T, Inokuchi T, Honma T, Itano S, Kawasaki E, Inada C, Aoki T, Tsumura N, Araki A, Mukae T, et al. Factors associated with advanced hepatic fibrosis in patients with various internal diseases: a multicenter community-based survey. Hepatol Res. 2018;48(11):882-92.

19. Savalia S, Emamian V. Cardiac arrhythmia classification by multi-layer perceptron and convolution neural networks. Bioengineering (Basel). 2018;5(2):E35

20. Cho S, Namkoong K, Shin M, Park J, Yang E, Ihm J, Thu VT, Kim HK, Han J. Cardiovascular protective effects and clinical applications of resveratrol. J Med Food. 2017;20(4):323-34.

21. Gabriel-Costa D. The pathophysiology of myocardial infarction-induced heart failure. Pathophysiology. 2018;25(4):277-84.

22. Amir E, Seruga B, Niraula S, Carlsson L, Ocana A. Toxicity of adjuvant endocrine therapy in postmenopausal breast cancer patients: a systematic review and meta-analysis. J Natl Cancer Inst. 2011;103(17):1299-309.

23. Aydiner A. Meta-analysis of breast cancer outcome and toxicity in adjuvant trials of aromatase inhibitors in postmenopausal women. Breast. 2013;22(2):121-9.

24. Cuppone F, Bria E, Verma S, Pritchard Kl, Gandhi S, Carlini P, Milella M, Nistico C, Terzoli E, Cognetti F, et al. Do adjuvant aromatase inhibitors increase the cardiovascular risk in postmenopausal women with early breast cancer? Meta-analysis of randomized trials. Cancer-Am Cancer Soc. 2008; 112(2):260-7.

25. Didari T, Mozaffari S, Nikfar S, Abdollahi M. Effectiveness of probiotics in irritable bowel syndrome: updated systematic review with meta-analysis. World J Gastroenterol. 2015;21(10):3072-84.

26. Moher D, Liberati A, Tetzlaff J, Altman DG. Preferred reporting items for systematic reviews and meta-analyses: the PRISMA statement. BMJ. 2009; 339:b2535.

27. Qi WX, Shen Z, Lin F, Sun YJ, Min DL, Tang LN, He AN, Yao Y. Incidence and risk of hypertension with vandetanib in cancer patients: a systematic review and meta-analysis of clinical trials. Br J Clin Pharmacol. 2013;75(4):919-30.

28. Sethi NJ, Feinberg J, Nielsen EE, Safi S, Gluud C, Jakobsen JC. The effects of rhythm control strategies versus rate control strategies for atrial fibrillation and atrial flutter: a systematic review with meta-analysis and Trial sequential analysis. PLoS One. 2017;12(10):e186856

29. Shepherd Kajawo MWMJ. Incidence of major complications after percutaneous native renal biopsies in adults from low-income to middleincome countries: a protocol for systematic review and meta-analysis. BMJ Open. 2018;8(4):e20891.

30. Fu Y, Lan T, Cai H, Lu A, Yu W. Meta-analysis of serum lactate dehydrogenase and prognosis for osteosarcoma. Medicine (Baltimore). 2018; 97(19):e741.

31. Kassa GM. Mother-to-child transmission of HIV infection and its associated factors in Ethiopia: a systematic review and meta-analysis. BMC Infect Dis. 2018;18(1):216

32. Peters $\mathrm{JL}$, Sutton AJ, Jones DR, Abrams KR, Rushton L. Contour-enhanced meta-analysis funnel plots help distinguish publication bias from other causes of asymmetry. J Clin Epidemiol. 2008;61(10):991-6.

33. Coombes RC, Hall E, Gibson LJ, Paridaens R, Jassem J, Delozier T, Jones SE, Alvarez I, Bertelli G, Ortmann O, et al. A randomized trial of exemestane after two to three years of tamoxifen therapy in postmenopausal women with primary breast cancer. N Engl J Med. 2004;350(11):1081-92.

34. Iwata H, Masuda N, Ohno S, Rai Y, Sato Y, Ohsumi S, Hashigaki S, Nishizawa $\mathrm{Y}$, Hiraoka M, Morimoto T, et al. A randomized, double-blind, controlled study of exemestane versus anastrozole for the first-line treatment of postmenopausal Japanese women with hormone-receptor-positive advanced breast cancer. Breast Cancer Res Tr. 2013;139(2):441-51.

35. van de Velde CJ, Rea D, Seynaeve C, Putter $H$, Hasenburg A, Vannetzel JM, Paridaens R, Markopoulos C, Hozumi Y, Hille ET, et al. Adjuvant tamoxifen and exemestane in early breast cancer (TEAM): a randomised phase 3 trial. Lancet. 2011:377(9762):321-31.

36. Baum M, Buzdar A, Cuzick J, Forbes J, Houghton J, Howell A, Sahmoud T. Anastrozole alone or in combination with tamoxifen versus tamoxifen alone for adjuvant treatment of postmenopausal women with early-stage breast cancer: results of the ATAC (Arimidex, Tamoxifen alone or in combination) trial efficacy and safety update analyses. Cancer. 2003;98(9):1802-10.

37. Buzdar $\mathrm{AU}$, Jonat $\mathrm{W}$, Howell $\mathrm{A}$, Jones $\mathrm{SE}$, Blomqvist $\mathrm{CP}$, Vogel $\mathrm{CL}$, Eiermann W, Wolter JM, Steinberg M, Webster A, et al. Anastrozole versus megestrol acetate in the treatment of postmenopausal women with advanced breast carcinoma: results of a survival update based on a combined analysis of data from two mature phase III trials. Arimidex Study Group. Cancer. 1998; 83(6):1142-52.

38. Smith I, Yardley D, Burris H, De Boer R, Amadori D, McIntyre K, Ejlertsen B, Gnant M, Jonat W, Pritchard Kl, et al. Comparative efficacy and safety of adjuvant Letrozole versus Anastrozole in postmenopausal patients with hormone receptor-positive, node-positive early breast Cancer: final results of the randomized phase III Femara versus Anastrozole clinical evaluation (FACE) trial. J Clin Oncol. 2017;35(10):1041-8.

39. Forbes JF, Cuzick J, Buzdar A, Howell A, Tobias JS, Baum M. Effect of anastrozole and tamoxifen as adjuvant treatment for early-stage breast cancer: 100-month analysis of the ATAC trial. Lancet Oncol. 2008:9(1):45-53.

40. Safra T, Kaufman B, Kadouri L, Efrat Ben-Baruch N, Ryvo L, Nisenbaum B, Evron E, Yerushalmi R. Everolimus Plus Letrozole for Treatment of Patients With HR + , HER2 - Advanced Breast Cancer Progressing on Endocrine Therapy: An Open-label, Phase II Trial. Clin Breast Cancer. 2018:18(2):e197-203.

41. Tjan-Heijnen VCG, van Hellemond IEG, Peer PGM, Swinkels ACP, Smorenburg CH, van der Sangen MJC, Kroep JR, De Graaf H, Honkoop AH, Erdkamp FLG, et al. Extended adjuvant aromatase inhibition after sequential endocrine therapy (DATA): a randomised, phase 3 trial. Lancet Oncol. 2017; 18(11):1502-11.

42. Colleoni M, Luo W, Karlsson P, Chirgwin J, Aebi S, Jerusalem G, Neven P, Hitre $E$, Graas MP, Simoncini E, et al. Extended adjuvant intermittent letrozole versus continuous letrozole in postmenopausal women with breast cancer (SOLE): a multicentre, open-label, randomised, phase 3 trial. Lancet Oncol. 2018;19(1):127-38.

43. Coates AS, Keshaviah A, Thürlimann B, Mouridsen H, Mauriac L, Forbes JF, Paridaens R, Castiglione-Gertsch M, Gelber RD, Colleoni M, et al. Five years of Letrozole compared with Tamoxifen as initial adjuvant therapy for postmenopausal women with endocrine-responsive early breast Cancer: update of study BIG 1-98. J Clin Oncol. 2007;25(5):486-92.

44. Kaufmann M, Jonat W, Hilfrich J, Eidtmann H, Gademann G, Zuna I, von Minckwitz G. Improved overall survival in postmenopausal women with early breast cancer after anastrozole initiated after treatment with tamoxifen compared with continued tamoxifen: the ARNO 95 study. J Clin Oncol. 2007;25(19):2664-70

45. O Shaughnessy J, Petrakova K, Sonke GS, Conte P, Arteaga CL, Cameron DA, Hart LL, Villanueva C, Jakobsen E, Beck JT, et al. Ribociclib plus letrozole versus letrozole alone in patients with de novo HR+, HER2- advanced breast cancer in the randomized MONALEESA-2 trial. Breast Cancer Res Tr. 2018;168(1):127-34.

46. Sonke GS, Hart LL, Campone M, Erdkamp F, Janni W, Verma S, Villanueva C, Jakobsen E, Alba E, Wist E, et al. Ribociclib with letrozole vs letrozole alone in elderly patients with hormone receptor-positive, HER2-negative breast cancer in the randomized MONALEESA-2 trial. Breast Cancer Res Tr. 2018; 167(3):659-69.

47. Coombes RC, Kilburn LS, Snowdon CF, Paridaens R, Coleman RE, Jones SE, Jassem J, Van de Velde CJ, Delozier T, Alvarez I, et al. Survival and safety of exemestane versus tamoxifen after 2-3 years' tamoxifen treatment (intergroup Exemestane study): a randomised controlled trial. Lancet. 2007; 369(9561):559-70

48. Boccardo F, Rubagotti A, Puntoni M, Guglielmini P, Amoroso D, Fini A, Paladini G, Mesiti M, Romeo D, Rinaldini M, et al. Switching to anastrozole versus continued tamoxifen treatment of early breast cancer: preliminary results of the Italian Tamoxifen Anastrozole trial. J Clin Oncol. 2005;23(22):5138-47.

49. Goss PE, Ingle JN, Pritchard KI, Ellis MJ, Sledge GW, Budd GT, Rabaglio M, Ansari RH, Johnson DB, Tozer R, et al. Exemestane versus anastrozole in postmenopausal women with early breast cancer: NCIC CTG MA.27--a randomized controlled phase III trial. J Clin Oncol. 2013;31(11):1398-404.

50. Phillips WJ, Johnson C, Law A, Turek M, Small AR, Inacio JR, Dent S, Ruddy T, Beanlands RS, Chow B, et al. Reporting of coronary artery calcification on chest $C T$ studies in breast cancer patients at high risk of cancer therapy related cardiac events. Int J Cardiol Heart Vasc. 2018;18:12-6.

51. Khosrow-Khavar F, Filion KB, Al-Qurashi S, Torabi N, Bouganim N, Suissa S, Azoulay L. Cardiotoxicity of aromatase inhibitors and tamoxifen in postmenopausal women with breast cancer: a systematic review and metaanalysis of randomized controlled trials. Ann Oncol. 2017;28(3):487-96.

52. Lintermans $A$, Neven P. Safety of aromatase inhibitor therapy in breast cancer. Expert Opin Drug Saf. 2015;14(8):1201-11. 
53. Early Breast Cancer Trialists' Collaborative Group (EBCTCG). Aromatase inhibitors versus tamoxifen in early breast cancer: patient-level meta-analysis of the randomised trials. Lancet. 2015;386(10001):1341-52.

54. Braithwaite RS, Chlebowski RT, Lau J, George S, Hess R, Col NF. Meta-analysis of vascular and neoplastic events associated with tamoxifen. J Gen Intern Med. 2003;18(11):937-47.

55. Henry ML, Niu J, Zhang N, Giordano SH, Chavez-MacGregor M. Cardiotoxicity and cardiac monitoring among chemotherapy-treated breast Cancer patients. JACC Cardiovasc Imaging. 2018;11(8):1084-93.

56. Fowkes FG, Murray GD, Butcher I, Heald CL, Lee RJ, Chambless LE, Folsom AR, Hirsch AT, Dramaix M, DeBacker G, et al. Ankle brachial index combined with Framingham risk score to predict cardiovascular events and mortality: a meta-analysis. JAMA. 2008;300(2):197-208.

57. Anderson R, Nel JG, Feldman C. Multifaceted role of Pneumolysin in the pathogenesis of myocardial injury in community-acquired pneumonia. Int J Mol Sci. 2018;19(4):E1147.

58. Guliyev O, Sayin B, Uyar ME, Genctoy G, Sezer S, Bal Z, Demirci BG, Haberal M. High-grade proteinuria as a cardiovascular risk factor in renal transplant recipients. Transplant Proc. 2015;47(4):1170-3.

59. Zhu J, Guo F, Zhang J, Mu C. Relationship between carotid or coronary artery calcification and osteoporosis in the elderly. Minerva Med. 2019;110(1):12-7.

60. Dasgupta P, Aitken JF, Pyke C, Baade PD. Competing mortality risks among women aged 50-79 years when diagnosed with invasive breast cancer, Queensland, 1997-2012. Breast. 2018:41:113-9.

61. Hoog J, Achenbach S. Summary of the ESC position paper on cancer treatment and cardiovascular toxicity. Herz. 2016;41(8):684-9.

62. Obi N, Eulenburg C, Seibold P, Eilber U, Thone K, Behrens S, Chang-Claude J, Flesch-Janys D. Associations between adjuvant radiotherapy and different causes of death in a German breast cancer cohort. Breast. 2018;38:75-80.

63. Zhu Q, Kirova YM, Cao L, Arsene-Henry A, Chen J. Cardiotoxicity associated with radiotherapy in breast cancer: a question-based review with current literatures. Cancer Treat Rev. 2018;68:9-15.

64. Sardar P, Kundu A, Chatterjee S, Nohria A, Nairooz R, Bangalore S, Mukherjee $\mathrm{D}$, Aronow WS, Lavie CJ. Long-term cardiovascular mortality after radiotherapy for breast cancer: a systematic review and meta-analysis. Clin Cardiol. 2017;40(2):73-81.

65. Feola M, Garrone O, Occelli M, Francini A, Biggi A, Visconti G, Albrile F, Bobbio M, Merlano M. Cardiotoxicity after anthracycline chemotherapy in breast carcinoma: effects on left ventricular ejection fraction, troponin I and brain natriuretic peptide. Int J Cardiol. 2011;148(2):194-8.

66. Lee K, Kang I, Mortimer JE, Sattler F, Mack WJ, Fitzsimons LA, Salem G, DieliConwright CM. Effects of high-intensity interval training on vascular function in breast cancer survivors undergoing anthracycline chemotherapy: design of a pilot study. BMJ Open. 2018;8(6):e22622.

\section{Publisher's Note}

Springer Nature remains neutral with regard to jurisdictional claims in published maps and institutional affiliations.

Ready to submit your research? Choose BMC and benefit from:
- fast, convenient online submission
- thorough peer review by experienced researchers in your field
- rapid publication on acceptance
- support for research data, including large and complex data types
- gold Open Access which fosters wider collaboration and increased citations
- maximum visibility for your research: over 100M website views per year
At BMC, research is always in progress.
Learn more biomedcentral.com/submissions

